\title{
“ADIAR O FIM DO MUNDO É EXATAMENTE SEMPRE PODER CONTAR MAIS UMA HISTÓRIA": NOTAS PARA UNA METODOLOGÍA EN PROCESO DE UNA FEMINISTA QUE SUEÑA CON POSTERGAR EL FIN DEL MUNDO
}

\section{"ADIAR O FIM DO MUNDO É EXATAMENTE SEMPRE PODER CONTAR MAIS UMA HISTÓRIA": Notes for an Ongoing Methodology of a Feminist Who Dreams of POSTPONING THE END OF THE WORLD}

\author{
Paola María Marugán-Ricart* \\ DOI: http://dx.doi.org/10.29043/liminar.v19il.807
}

\begin{abstract}
Resumen: En este artículo propongo una metodología feminista que articule los estudios culturales, los estudios feministas y los estudios de blanquitud, producidos desde el sur global, con el fin de reflexionar acerca del compromiso que implica el trabajo intelectual político, el mestizaje como campo de acción de diversas luchas, la relación entre las artistas y la investigadora, "la escritura auto-litigante" como práctica responsable ineludible, el contextualismo radical y lo político en la selección de los caminos teóricos.
\end{abstract}

Palabras clave: prácticas artísticas, procesos creativos, metodología feminista, cultura, identidad, blanquitud, interseccionalidad, mestizaje, prácticas escriturales.

\begin{abstract}
In this article, I propose a feminist ideology that weaves together cultural studies, feminist studies, and studies of whiteness, produced in the global south, in order to reflect upon the commitment of political intellectual work, mix-race identity as a field of action in various struggles, the relationship between researcher and artists, "self-litigation writing" as an unavoidable responsible practice, radical contextualism, and the political in the selection of theoretical paths.
\end{abstract}

Keywords: artistic practices, creative processes, feminist methodology, culture, identity, whiteness, intersectionality, mix-race identity, writing practices.

\footnotetext{
* Paola María Marugán Ricart. Maestra en Arte y Cultura Contemporánea por la Universidade do Estado do Rio de Janeiro (UERJ), Brasil. Estudiante de doctorado en Estudios Feministas en la Universidad Autónoma Metropolitana, Unidad Xochimilco (UAM-X), México. Temas de especialización: prácticas artísticas experimentales, intervenciones feministas en el arte, epistemologías feministas, estudios culturales. Correo electrónico: paolamarugan@gmail.com. ORCID: https://orcid.org/0000-0002-0767-1988
}

Enviado a dictamen: 13 de abril de 2020. Aprobación: 14 de septiembre de 2020. 


\section{Introducción}

$\amalg$ n este texto se presenta una metodología en proceso de una investigadora que sueña con postergar el fin del mundo escribiendo. La repetición ad infinitum de imágenes apocalípticas del mundo, enunciadas como verdades absolutas en redes sociales y medios de comunicación, busca que desistamos de nuestros propios sueños, como señala Ailton Krenak, escritor y activista indígena brasileño oriundo de la aldea Krenak, localizada en una de las márgenes del río Doce, estado de Minas Gerais, Brasil. Se trata de un río aparentemente ${ }^{l}$ asesinado por la compañía Samarco Mineração S.A. el trágico 5 de noviembre de 2015. Aquellas imágenes, que sin duda tuvieron un fuerte impacto en la sociedad brasileña, no extirparon la voluntad de seguir soñando, la urgencia de continuar escribiendo. Antes bien, aquellos enunciados apocalípticos fortalecieron las palabras de Krenak: "postergar el fin del mundo es exactamente poder contar una historia más" (Krenak, 2019:13).

Mi investigación de doctorado ${ }^{2}$ pretende ser una piedra/una historia más en el camino, que impida a la "humanidade zumbi" (Krenak, 2019) cumplir su último objetivo: obliterar la pulsión vital de absolutamente todos los seres vivos de este planeta. El título de la investigación es "Racialidad, mujeres y nación en el Brasil del siglo XXI. Análisis de las prácticas artísticas de Ana Lira y el Grupo Cultural Balé das Iyabás".

En esta investigación analizo una serie de prácticas artísticas procesuales y des-localizadas de los circuitos institucionales que devienen, en sí mismas, dispositivos de intercambio de experiencias y saberes inscritos en una dimensión micropolítica. El análisis se centrará en las prácticas artísticas que se despliegan de los procesos creativos de Vivências ${ }^{3}$ del Grupo Cultural Balé das Iyabás (formado por Ludmila Almeida y Sinara Rúbia), en el barrio de Santa Teresa de la ciudad de Río de Janeiro, y TERRANE ${ }^{4}$ de la artista Ana Lira, localizado en el sertão (región semiárida) del estado de Pernambuco, Nordeste, Brasil. En ambos casos analizaré de qué maneras estos grupos de mujeres están respondiendo a la violencia estructural, constitutiva del modelo de nación brasileña, y generan proyectos emancipatorios con perspectivas feministas que implican la participación de una red microscópica de relaciones entre mujeres de un mismo territorio.

La pregunta principal de investigación es ide qué maneras las prácticas artísticas de Ana Lira y el Grupo Cultural Balé das Iyabás producen subjetividades políticas que interpelan al modelo de nación brasileña colonial, racista y esclavista en sus formas contemporáneas? El marco teórico y metodológico que propongo articula los estudios culturales y los estudios feministas, producidos desde diferentes sures, y los estudios de blanquitud, para centrarme únicamente en los debates que se están llevando a cabo en Brasil. La decisión de vincular estos tres marcos teórico-prácticos responde a la inquietud investigativa que surgió durante los dos primeros años del doctorado: ¿cómo desplazar el discurso semiótico — propio de la historiografía y la crítica del arte- para otros marcos de análisis desde los cuales poder producir narrativas desobedientes ${ }^{5}$ de los procesos creativos de TERRANE y Vivências, a partir de la (re)interpretación de las múltiples relaciones entre cultura-identidad-poder que se dan en esos proyectos? Y que tales narrativas teóricas, en definitiva, tengan la voluntad política de contribuir a transformar el mundo.

El compromiso que implica el trabajo intelectual político desde los estudios culturales se potencializa en la articulación con los estudios feministas, en el sentido de elaborar un pensamiento feminista, situado, relacional y complejo, desde las prácticas inter y transdisciplinares que las mujeres realizan en diferentes localizaciones del sur. Prácticas que son epistemologías en sí mismas y deben ser leídas desde sus propios contextos. Así, lo que presento a continuación es una reflexión sobre el encuentro de estos dos marcos teóricos, que a su vez operan como praxis, proporcionando luz en las relaciones surgidas del trinomio cultura-identidad-poder y magiar, así, futuros posibles. ${ }^{6}$ Me interesa el verbo magiar (en lugar de inventar) por la genealogía del concepto y su relación con las mujeres, como señala Silvia Federici:

La tarea era imposible y pronto la Inquisición perdió interés en el proyecto, convencida a estas alturas de 
que la magia popular no era una amenaza para el orden político. Los testimonios que recogió revelan, sin embargo, la existencia de múltiples intercambios entre mujeres en temas relacionados con curas mágicas y remedios para el amor, creando con el tiempo una nueva realidad extraída del encuentro entre tradiciones africanas, europeas e indígenas (Federici, 2004:167-168).

Posteriormente, expongo algunas de las ideas sobre el mestizaje, como campo de enfrentamiento en la lucha por los significados, cuerpos, prácticas, política y poder, visto desde los estudios de blanquitud y, por otro lado, la relación entre las sujetos-creadoras y mi localización como investigadora, para pensar la práctica escritural en la investigación. La última parte del texto está dedicada a reflexionar sobre el contextualismo radical como herramienta investigativa planteada desde los estudios culturales, y radicalizada por el pensamiento feminista, para finalmente cerrar el texto con algunas reflexiones y sentires de este proceso que continúa su camino.

\section{El encuentro entre los estudios culturales y los feminismos podrían magiar futuros posibles}

El punto de partida es problematizar la concepción clásica de teoría para llegar a lo que Stuart Hall propone en su "go on theoring", es decir, "redefinir constantemente nuestros conceptos, dejar de pensar de cierto modo y empezar a pensar de otro, más adecuado a nuestro propio contexto" (Hall, 2011:30). A mi modo de ver, el concepto de desplazamiento atraviesa tanto los procesos creativos como la producción de subjetividad de las artistas, y la mía como investigadora, por lo que la propuesta teórico-metodológica debería también incorporar ciertos desplazamientos que acompasasen los ritmos teóricos, artísticos y políticos.

Todos necesitamos traducir constantemente ideas y conceptos en situaciones específicas: esta continua necesidad de traducción es, de nuevo, lo que he denominado "teorizar". Ello no significa producir "teorías", que en mi concepción se relaciona más con la extensión de un solo paradigma hasta donde es lógicamente posible. Esto también puede hacerse, pero no es mi trabajo. No ambiciono tener un pensamiento filosófico de esta índole. Me interesa más comprender cómo ajustar ciertos términos y conceptos para encarar situaciones particulares, coyunturas específicas (Hall, 2011:30).

Así, en esta investigación me interesa conectar el "go on theoring" de Hall, esto es, la idea de teorizar como un proceso - a partir de ajustes conceptuales, leídos como desplazamientos flexibles, cambiantes y fluidos-, con las prácticas teórico-discursivas de feministas negras, chicanas, anticoloniales y descoloniales, que conciben la teoría desde y con el cuerpo, como un quehacer más de la vida cotidiana, frente a los discursos filosóficos abstractos, elaborados por el sujeto varón, blanco, occidental u occidentalizado, con pretensiones universalistas. Esta producción teórica en proceso es personal, encarnada, contextual y política, en el sentido de responder al entramado de relaciones de poder que constituyen los procesos de producción de vida.

Los estudios culturales y los estudios feministas son campos de producción de conocimiento dedicados al análisis de las relaciones de poder, un poder que es complejo, irregular, cambiante, contradictorio y que opera dentro de una constelación expandida de relaciones sociales, políticas, económicas, culturales y espirituales. Ambos se preocupan por "producir conocimiento crítico como práctica política" (Hall, 2011), asumiendo las tensiones y contradicciones que conlleva desarrollar una práctica política intelectual responsable en el mundo que habitamos. Se trata, por tanto, de contar las mejores historias posibles (Grossberg, 2017), las más peligrosas (Garzón, 2018a), aquellas que posterguen el fin del mundo (Krenak, 2019), a partir de preguntas incómodas e inusitadas que provoquen otras reflexiones sobre los objetos de saber y los espacios de poder que aquí propongo: los procesos creativos de Vivências y TERRANE, inscritos en la idea de nación brasileña como un todo complejo, contradictorio y cambiante.

Mi intención es analizar los procesos creativos e investigativos como parte de los procesos de produc- 
ción de vida de las artistas, observando de qué maneras las experiencias de tales procesos se traducen en conciencia feminista, antirracista y anticolonial para responder, así, a mi pregunta de investigación. De esta manera, los estudios culturales me parecen un marco teórico idóneo para este tipo de análisis — articulado con marcos de pensamiento feminista-, por concebir la cultura "como el medio donde suceden las articulaciones y relaciones de poder mismas" (Grossberg, 2017:28), a diferencia de cómo ha sido comprendida por la antropología clásica, como el conjunto de formas de vida que organizan las sociedades.

\begin{abstract}
Ahora bien, los estudios culturales no son sobre la cultura. No son sobre convertirse en un intérprete del texto cultural, o del mundo imaginativo y comunicativo. Se trata, más bien, de las interconexiones entramadas de la cultura con las estructuras sociales, transiciones históricas, organizaciones económicas, relaciones sociales e instituciones políticas. En este orden de ideas, Stuart alguna vez dijo "si quieres estudiar la cultura, estudia todo menos la cultura" (Grossberg, 2017:28)
\end{abstract}

Por lo tanto, en el marco de los estudios culturales y feministas, propongo un análisis interdisciplinar de los procesos creativos de Vivências y TERRANE que abarque la complejidad de dichos procesos (concebidos como un todo e inscritos en un conjunto complejo de relaciones cambiantes y contradictorias, que se materializan en un contexto determinado), desmantelando las estructuras binarias que organizan nuestro sistema-mundo colonial y problematizando las voces de autoridad que han dictaminado qué es conocimiento y quién puede producirlo. En relación con esto último, una referencia a tener en cuenta son las cuestiones que planteó la artista Grada Kilomba en su exposición "Grada Kilomba: desobediências poéticas”, en la Pinacoteca de São Paulo:

¿Qué ocurre cuando la producción de conocimiento universal es contada por otros cuerpos? ¿Qué es conocido como conocimiento? ¿Cuál es el conocimiento que conozco y por qué lo conozco?
¿Por qué no tengo acceso a otros conocimientos? ¿Por qué ese conocimiento es visto como universal? ¿Me siento representada en ese conocimiento universal? (Pinacoteca de São Paulo, 2019).

Alzar la voz con este tipo de preguntas es recordar(nos) que existen múltiples formas de decir lo social, más allá de la impronta positivista que todavía existe en las prácticas de las ciencias sociales y las humanidades; apelar a la "imaginación sociológica" (magiar lo clásico de la sociología como disciplina) es comprender que "renovar la escritura de las ciencias sociales no consiste pues en abolir toda regla, sino en darse libremente nuevas reglas" (Jablonka, 2016:18). A mi parecer, el paradigma científico clásico se encuentra obsoleto por su incapacidad de responder a las complejas demandas que las sociedades están poniendo en cuestión actualmente. De ahí que una práctica intelectual responsable pase por la transformación de las disciplinas, el desmantelamiento de las relaciones binarias y la producción de un conocimiento inter/transdisciplinar que permita narrar las historias que urgen ser contadas, quizá las más peligrosas e indóciles, aquellas historias que produzcan un conocimiento útil, exponiendo las relaciones que emergen de la articulación cultura-identidad-poder con el fin de contribuir a transformar nuestro mundo. De este modo, el desplazamiento teórico-práctico que propongo realizar está relacionado con la voluntad de habitar los "entres" o intersticios de las disciplinas, mostrando las articulaciones imbricadas entre los objetos de estudio en tanto procesos creativos, las sujetos-creadoras y el contexto, para así producir un conocimiento complejo, riguroso, subjetivo y apasionado.

Los estudios feministas son:

[...] campos de cuestionamiento inscritos en procesos y prácticas discursivas y materiales en un territorio poscolonial. Representan una lucha por los marcos políticos de análisis, los significados de los conceptos teóricos, la relación entre teoría, práctica y experiencia subjetiva; representan una lucha por las prioridades políticas y las formas de movilización (Brah, 2004:114). 
Son producidos desde los sures y articulados con los estudios culturales, como una práctica teórica que incita la imaginación política para intentar transformar la sociedad, y proponen una ecuación diferente para la (re)definición de las categorías, el trabajo de campo, las articulaciones, el contexto y el análisis estético-ético de la investigación. En la introducción de "Feminismo, cultura y política. Prácticas irreverentes”, Mónica Cejas (2016) expone las conexiones entre los estudios culturales y el feminismo descolonial latinoamericano como posicionamiento crítico frente a las relaciones de poder articuladas en nuestro sistema-mundo moderno, eurocéntrico, capitalista y colonial, que habitamos y nos habita.

- Conciben una práctica intelectual en relación con intervenciones políticas concretas para "desatar" (destejer para tejer de otro modo...) [...];

- Contribuyen a la reestructuración de los paradigmas tradicionales;

- Son interdisciplinarias [...];

- Se interesan por la articulación de la cultura con dispositivos concretos del poder (y de la resistencia);

- Se oponen a la violencia epistémica en la investigación;

- Coinciden en la importancia de articular las categorías de identidad con otros aspectos de la vida social y política [...];

- Son posestructuralistas al cuestionar los modelos de subjetividad e identidad existentes [...];

- Coinciden en que la producción de conocimiento no se genera sólo en la academia, sino también en otros espacios sociales [...] desde la crítica a la modernidad, concuerdan entonces en los vínculos que unen teoría y praxis;

- Dan importancia al lugar desde donde se habla $[\ldots]$;

- Acuerdan en su antirracismo y lucha contrahegemónica [...];

- Reclaman el olvido del colonialismo dentro de la teoría tradicional y la importancia de las catego- rías de raza y etnicidad [...] Y algo muy importante: el género es también producto de la colonialidadmodernidad (Cejas, 2016:14-15).

Desde diversos campos de estudio, las teóricas feministas están proponiendo análisis multidisciplinares de los discursos y problematizando las relaciones de poder, inscritas en las concepciones esencialistas que definen "identidad" y "diferencia" como categorías fijas, inmutables y ahistóricas. Siguiendo a Nelly Richard, entiéndase por discurso "un conjunto múltiple de prácticas significantes inscritas en materialidades diversas (no exclusivamente lingüísticas) y, también, el campo de realización simbólica, material y comunicativa de las ideologías en las que surgen los conflictos de interpretación que se libran en torno al uso social y político de los signos" (Richard, 2009:76). De acuerdo con esto, los procesos creativos de Vivências y TERRANE pueden ser considerados discursos en tanto campos de resignificación "simbólica, material y comunicativa" que responden a conflictos generados por el "uso social y político de los signos". Es en los procesos creativos -concebidos como discursos y praxis-donde se da una lucha por los significados desde las prácticas artísticas; es en los procesos creativos - concebidos como textos- donde las artistas producen sus proyectos emancipatorios, por medio de la enunciación de un "yolibre", problematizando los significados que la nación impone en el cuerpo de las mujeres.

En los contextos latinoamericanos se están llevando a cabo intensos debates, pensando identidad y diferencia desde una lente interseccional, en esa articulación entre estudios culturales y feministas, generando brechas profundas en los marcos epistemológico, ontológico y ético modernos, produciendo "un campo de producción del conocimiento crítico y lugar de intervención y transformación sociopolítica y epistémica" (Cejas, 2016:14). Desde realidades muy diversas, las mujeres (feministas o no) están problematizando la cultura desde la propia cultura, pensando las relaciones de poder y los marcadores de opresión que producen sus cuerpos y vidas. 
En consecuencia, vale la pena reflexionar una vez más sobre icuál podría ser la relación entre mujeres, cultura y poder? ¿Para quiénes es significativa esa relación? ¿El llamado giro cultural de la lucha feminista puede aliarse con los estudios culturales? Si todo lo anterior es afirmativo iqué tipo de conocimiento y prácticas se desprenden de la intersección entre estudios culturales y feminismo? Aún más: icómo es representada, estudiada y analizada la relación entre feminismo y estudios culturales desde el propio feminismo y desde los mismos estudios culturales? (Garzón et al., 2014:161).

En las disputas por el poder y los significados desde los estudios culturales y los feministas, María Teresa Garzón (2018a) propone "defender fantasía” como modelo de crítica cultural, desde los contextos latinoamericanos, partiendo de la idea de que "el poder es cultura y la cultura es poder" (Restrepo, 2009). "Fantasía es el terreno privilegiado donde nos jugamos la sobrevivencia, la resistencia y el cambio, luchando siempre contra su cooptación mercantil, su banalización y su traducción en teorías ‘pop”' (Garzón, 2018a:87). A mi modo de ver, "defender fantasía” es comprender que no existe un modelo de crítica cultural feminista sistematizado, fijo y universal (Richard, 2009); "defender fantasía” requiere de la imaginación política para magiar nuevos parámetros analíticos de la cultura y, a través de ella, que propongan conexiones inusitadas e iluminen el enmarañado y frecuentemente enmascarado sistema de relaciones de poder, por medio de prácticas interdisciplinares que inviten a redefinir las categorías, para pensar de otro modo más apropiado a los contextos.

Así, entiendo que tanto los estudios culturales como los feministas son proyectos intelectuales en los que la lucha teórica es indisociable de la política, entendida como praxis. Ambos agitan las arquitecturas disciplinarias de la epistemología moderna-colonial-capitalista, con el fin de intervenir el mundo, comprendiendo que los posicionamientos nunca son absolutos (antes bien, están siempre sujetos a modificación, ya que el mundo fluye en un devenir constante), asumiendo la modestia necesaria, tras comprender que es en el marco de la micropolítica donde las investigadoras actuamos e intervenimos, reconociendo que las verdades y los teorías son conocimientos situados y encarnados, disputados y coyunturales.

Desde este marco teórico político pretendo analizar los procesos de creación de TERRANE y Vivências, conviviendo con las contradicciones y las tensiones que esta decisión implica, y también por mi lugar de enunciación. La práctica intelectual política es un proceso cargado de muchas preguntas, planteadas desde la responsabilidad, desde una conciencia política; parafraseando a Grada Kilomba, ahora que soy consciente del poder de la palabra, iqué es lo que yo puedo hacer con ese saber? Es la pregunta ética que aquí se impone.

\section{Reflexiones en torno a lo mestizo, la blanquitud y la escritura en la investigación}

En este apartado pretendo justificar la importancia de incluir, en el marco teórico-metodológico, algunos de los debates llevados a cabo desde los estudios de blanquitud en el contexto brasileño y, posteriormente, elaborar una reflexión en torno a la posición que ocupo como investigadora, en relación con las sujetos-creadoras actuantes en esta investigación.

¿Por qué deviene relevante la pregunta sobre lo mestizo en las prácticas culturales del presente? El mestizaje, como mito fundacional organizador de la geopolítica brasileña, fue engendrado por la violencia y la dominación, a pesar de haber sido producido históricamente bajo retóricas reconciliatorias. Observar lo mestizo en Brasil es comprender de qué maneras se ha organizado la nación territorialmente, conforme al marcador racial. ${ }^{7}$ A mi modo de ver, el mito de la democracia racial $^{8}$ devino la posibilidad material para alcanzar un pacto civilizatorio, a partir de una narrativa de futuro blanco y conforme a lógicas sociales de una falsa convivencia armónica. Así, comprendo que la democracia racial se produjo como un mito apaciguador de las relaciones sociales, sostenido por un sistema estructural profundamente violento que mantiene sus cimientos fortalecidos por las políticas depredatorias del actual 
presidente. ${ }^{9}$ Como señaló Abdias Nascimento, ya en la década de los setenta:

\begin{abstract}
El prejuicio de color, la discriminación racial y la ideología racista permanecieron disfrazados bajo la máscara de la llamada "democracia racial", ideología con tres principales objetivos: 1. Impedir cualquier reivindicación basada en el origen racial de aquellos que son discriminados por ser descendientes del negro africano; 2. Asegurar que todo el resto del mundo jamás tome conciencia del verdadero genocidio que se perpetra contra el pueblo negro del país; 3 . Aliviar la conciencia de culpa de la propia sociedad brasileña que ahora, más que nunca, está expuesta a la crítica de las naciones africanas independientes y soberanas, de las cuales el Brasil oficial pretende ganar ventajas económicas (Nascimento, 2018[1976]:34).
\end{abstract}

A mi parecer, la subjetividad mestiza surgió como un producto del imaginario nacional que, lejos de ser independentista, abogó por la continuidad del modelo colonial con matices locales. Sin embargo, su dimensión performativa permite que sea reformulada, pensando los procesos de racialización y desplazando al sujeto blanco del centro del poder. Las fronteras para determinar lo mestizo son muy complejas, por lo que acaban siendo los Estados-nación los que detentan el poder de la demarcación territorial y corporal por medio de un conjunto de políticas públicas que definen ciudadanía. De ahí que el mestizaje sea un campo de lucha que implica significados, cuerpos, prácticas, política y poder.

Una parte de estos debates se están llevando a cabo desde los estudios de blanquitud, repensando lo mestizo como lugar de poder, considerando la complejidad de las prácticas culturales brasileñas y asumiendo la multivocalidad que conforma el país, para desnaturalizar el alto prestigio social del sujeto blanco (Sovik, 2005). La identidad racial blanca se ha construido histórica y socialmente como el lugar de los privilegios simbólicos y materiales; el sujeto blanco detenta una posición de poder desde la cual observa cómodamente la(s) otredad(es); ser blanco es considerado el estándar normativo único, el modelo de ser humano ideal, por lo que su identidad racial no necesita ser marcada. Así, las personas blancas nacen, crecen y viven en una suerte de confinamiento social que garantiza un ambiente racialmente relajado (Cardoso, 2010; Silva Bento, 2002; Sovik, 2005).

Las principales líneas de estos debates se resumen en los siguientes puntos:

- La invisibilidad racial es una de las características principales de la blanquitud. Tan pronto como las personas blancas son confrontadas y racializadas, se produce en ellas un gran impacto cuyos resultados en muchos casos son la negación, el contraataque o la acusación del llamado "racismo al revés".

- El pacto de silencio entre las personas blancas a la hora de reconocer el lugar que ocupan en la sociedad; en general, existe una dificultad para admitir que son parte esencial de la permanencia de las desigualdades.

- Existe un ingrediente narcisista que valora y refuerza las características fisiológicas de las personas blancas, así como la autoestima y la confianza.

- Blanquitud es sinónimo de humanidad, poder, belleza, modernidad y norma.

- Blanquitud es el programa moderno-colonial que alcanza las dimensiones de lo social, corporal, subjetivo, espiritual, territorial, económico y político; estructura el mito de la democracia social organizador del modelo de nación brasileña.

Lourenço Cardoso (2010) distingue dos tipos de blanquitud: crítica y acrítica. La primera desaprueba el racismo públicamente, asumiendo que existen privilegios garantizados por el hecho de pertenecer a ese grupo social. La segunda, la blanquitud acrítica, no rechaza el racismo, tampoco admite la discriminación racial, y considera que el sujeto blanco se encuentra en una condición especial respecto al resto de los seres (no) humanos. Así, me pregunto: ide qué maneras transitar de la blanquitud crítica a la blanquitud antirracista en esta investigación (y en todas las otras dimensiones de la vida)? Problematizar individual y colectivamente la 
noción de privilegios es fundamental para desvelar los prejuicios que sustentan las teorías de la destrucción/ saqueo y los beneficios materiales y simbólicos adscritos a la blanquitud como programa.

A mi parecer, el sujeto feminista antirracista debería ser construido con base en la lucha de tales privilegios - que sean derechos para todas y no únicamente para un grupo determinado- y en el reconocimiento de la incompletitud, la alteridad, la dignidad y la interdependencia entre las personas. ¿Cómo abordar las diferencias que nos separan? ¿Y si concibiéramos las diferencias como singularidades en lugar de oposiciones? (Ferreira da Silva, 2016). Entiendo que así pensaríamos distinto, estaríamos inventando una ética otra (friccionando la gramática moderna-colonial), que nos permitiría definir un sujeto político feminista y antirracista a partir de todo aquello que nos separa, ${ }^{10}$ una definición del "nosotras" plural, compleja y no exenta de tensiones.

Denise Ferreira da Silva (2016) señala que el fin del mundo, tal y como lo conocemos, está disolviendo la idea de colectividad humana, tanto "la propia" (europea) como "las extranjeras" (las otredades). En consecuencia, se pregunta cómo pensar la socialización por fuera del texto moderno.

En vez de un Mundo Ordenado, pudiésemos imaginar El Mundo como una Plenitud, una composición "infinita" en que cada singularidad existente esté sujeta a convertirse en una expresión posible de todos los otros existentes, con los cuales ella [la Plenitud] esté enmarañada más allá del espacio y del tiempo (Ferreira da Silva, 2016:59).

Esta filósofa brasileña propone concebir la diferencia sin separabilidad para accionar el pensamiento en el afuera del encuadre moderno. Y es en este marco de pensamiento-acción donde me interesa ubicar la discusión sobre el ejercicio escritural de esta investigación, para elaborar una reflexión en torno a la relación entre mi figura, sujeto-investigadora, y las sujetos-creadoras actuantes, partiendo de comprender nuestras diferencias como singularidades en sí mismas, tensionando el marco de decidibilidad moderno-colonial y asumiendo las relaciones de poder inevitables que se dan en esta relación.

Así, percibo que esta (re)ubicación corporal-investigativa que (me) propongo/impongo conlleva un proceso cargado de muchos interrogantes, ya que implica desarrollar lo que María Teresa Garzón (2018b) llama una "escritura auto-litigante", es decir, salir de mi zona de confort para producir una escritura de intervención contra mí misma.

¿Podría una escribir en su contra, escribir contra sí misma? Se pregunta Valeria Flores en su ya clásico ensayo: "Escribir contra sí misma: una microtecnología de subjetivación política” (2010). Y continúa: ¿Qué procesos de desidentificación del yo se activan? ¿Qué empresa política -y de producción de conocimiento- podría deducirse de una escritura que litigue contra sí, contra Una, contra la sedimentación de un yo que tiende a estabilizarse? (Flores, 2010, p. 21l. El agregado es mío). Y aún más, desde esa escritura auto-litigante, es posible tan siquiera pensar en un "nosotras" teniendo en cuenta el cuestionamiento previo a las mujeres blancas, en 1982, que formula Hazel V. Carby (2012, p. 243): "ia qué os referís exactamente cuando decís "NOSOTRAS?". Entonces, en el momento en que la batalla real contra la opresión empieza en la piel, ies posible un "hacer" feminista descolonial, en nuestra Abya Yala, crítico a la blanquitud, cuando has sido construida y sigues siéndolo como una mujer blanca? ¿Sería esto escribir contra sí misma? ¿Una apuesta miope tal vez? O iestamos en el territorio donde habita el oxímoron? (Garzón, 2018b:1-2).

El ejercicio de escribir contra una misma deviene inevitable por el hecho de haber nacido en el Estado español, estar realizando el doctorado en México e investigando sobre Brasil y contando, además, con una credencial de estudiante universitaria cuya numeración acaba en 1492, un detalle anecdótico cargado de fuerte simbolismo. El desafío implica un proceso de aprendizaje sobre cómo habitar las contradicciones 
que surgen entre mi identidad ${ }^{11}$ y mi práctica, para producir conocimiento entre la construcción y la contradicción. Esta "escritura auto-litigante" atañe justamente a la necesidad de desobedecer ciertos valores éticos, sociales y culturales (aparentemente estables e inmutables y supuestamente universales) que me han formado como persona oriunda del norte global y con privilegio de blanquitud. El desafío de enunciarme feminista desde dicha localización tiene que ver con librarle la batalla a ese sujeto político hegemónico que habita en muchas de nosotras (feministas europeas). Europa es una ficción material ${ }^{12}$ muy compleja y cargada de contradicciones, con la que irremediablemente tengo que identificarme, para "asumir nuestra responsabilidad histórica" (Garzón, 2018a:97).

Esa responsabilidad implica además reconocer los límites que una investigación de este tipo impone, y no me refiero a las condiciones materiales (espacio, tiempo y financiación), sino más bien a comprender que los procesos creativos de TERRANE y Vivências están atravesados por relaciones que no pasan por el filtro de la razón moderna; relaciones en el plano de lo sutil que el paradigma científico no alcanza a organizar, por lo que aceptar ese terreno fronterizo es saber que el conocimiento producido aquí será sin garantías.

Mi relación con las sujetos-creadoras parte de una tentativa de compartir nuestros conocimientos por medio de diálogos que se han dado principalmente por correo electrónico - en el caso del Grupo Cultural Balé das Iyabás - y por vía telefónica y personal —en el caso de Ana Lira-. El mes de julio de 2019 participé en las XIV Jornadas Nacionales de Historias de las Mujeres y el IX Congreso Iberoamericano de Estudios de Género, en Mar del Plata (Argentina), donde presenté una ponencia titulada "Vivências: un ensayo de otros mundos posibles", que fue publicada en las actas del encuentro (Marugán, 2019a) y que compartí con Sinara Rúbia y Ludmila Almeida. Las artistas enviaron de vuelta una respuesta calurosa y de gratitud. El diálogo con Ana Lira es más fluido ya que nos une una relación de amistad que va más allá de la investigación, pero que a su vez se ha fortalecido gracias a esta. Ana y yo pensamos y escribimos juntas sobre TERRANE (formato entrevista) en la revista Cadernos de Subjetividade de la PUC-SP (Lira y Marugán, 2020). Además, Ana presentó el proceso creativo de TERRANE en el marco de DEVENIRES, el encuentro artístico feminista que curé en el Museo Universitario del Chopo, en 2020 en la Ciudad de México. ${ }^{13}$

En este conversatorio, Ana Lira llamó la atención sobre la necesidad de articular redes afectivas para desarrollar proyectos del tipo que está realizando. Sin esas redes, TERRANE no sería posible. Del mismo modo considero que sin las redes del Balé das Iyabas, Sinara Rúbia y Ludmila Almeida, no sería posible llevar a cabo las Vivências con la potencia y la afectación que acontecieron. Esa articulación de redes afectivas es una apuesta política por una forma de producir arte, y de igual manera es política la decisión de generar redes teórico-afectivas por medio de esta investigación. Por esto concibo la ruta teórica como una elección política; como señala Sara Ahmed, "las citas son memoria feminista" (2017:33) $y$, en consecuencia, la vocación genealógica en una investigación feminista es un compromiso ineludible. Las investigadoras, artistas y escritoras con quienes dialogo, y gracias a las cuales articulo la producción de conocimiento de esta investigación, son oriundas del llamado sur global, principalmente de Brasil y Abya Yala. Mi interés radica en contribuir modestamente al diálogo entre esos dos contextos entre los cuales, por causa de tener lenguas diferentes, la comunicación pareciera ser menos fluida. Siguiendo a Ahmed, concluiría este apartado afirmando que esta investigación es personal, "lo personal es teórico" (Ahmed, 2017:25) y lo teórico es político.

\section{Contextualismo radical: teorizar desde lo concreto. Un eterno proceso de aprendizaje}

Un desafío: teorizar desde lo concreto, produciendo conocimiento contextual del sertão nordestino y de una de las realidades que constituyen la ciudad de Río de Janeiro como un todo, desde un yo-investigadora situado, reconociendo los límites de la investigación — como 
señalé anteriormente-, evitando ejercer una vez más la tan conocida violencia epistémica y comprendiendo que los contextos producen los procesos creativos, así como estos intervienen en los contextos. iUn eterno proceso de aprendizaje!

El barrio de Santa Teresa —en extensión, la zona norte de Río de Janeiro- y el sertão nordestino son dos espacios geográficos y geopolíticos dentro del territorio brasileño con especificidades muy concretas; están constituidos por dos matrices culturales distintas con ciertas conexiones en el orden de lo simbólico; son territorios que operan como epistemologías de un sur del sur global; son lugares engendrados por procesos de experimentación obligatoria, frente a las condiciones (in)humanas de producción de vida, por causa de los procesos de estigmatización y subalternización a los que han sido sometidos históricamente; se encuentran inscritos en genealogías con vasos comunicantes entre los quilombos,${ }^{14}$ los terreiros, ${ }^{15}$ las cosmogonías indígenas y las asociaciones feministas, allá donde los feminismos - en el caso de ser nombrados - necesariamente sean en plural; son contextos que exigen la honestidad de quien pretende investigarlos, ya que no todas las relaciones pasan el filtro de la razón moderna; la ciencia no alcanza a elaborar ciertos fenómenos que habitan el campo de lo sutil, por lo que cualquier aproximación siempre será sin garantías; representan universos propios que desajustan el imaginario homogéneo de lo que es la nación brasileña y, a su vez, responden a las imposiciones de esa nación que los relegó al mundo de los incivilizados (menos humanos); son contextos particulares que presentan modos de pensar, sentir, hacer y existir desde lo concreto.

Por lo tanto, en mis análisis intentaré comprender de qué maneras esas prácticas llevan inscritas las marcas de sus propias condiciones históricas, políticas, sociales y afectivas; evitaré llevar a cabo un enfoque analítico de los procesos creativos, en tanto objetos opacos, extraídos de un marco histórico predefinido, y más bien valoraré esas poéticas desde sus especificidades culturales, sociales, políticas, históricas y subjetivas, que son asimismo mutables y contingentes. Desde los estudios culturales, la realidad es concebida como una totalidad compleja en constante reformulación, recreación y rearticulación (Grossberg, 2009), por lo que reflexionar contextualmente sobre ella:
No significa poner, como sucede frecuentemente, el contexto en el último capítulo como una forma de telón de fondo o marco interpretativo. Se trata de ver el contexto tanto como el objeto del análisis como la fuerza que determina nuestro análisis. Entender el contexto como un campo multidimensional de relaciones, es de lo que se trata los estudios culturales; no se trata de entender la cultura sino de comprender el contexto con la cultura como elemento absoluta- mente vital y, como lo es para muchos, la manera por la que entramos al contexto. Así, no debemos pensar el contexto como una entidad fija, estable, geográfica y temporalmente predefinida, ni tampoco como un caos desordenado y aleatorio. En su lugar, debemos entender el contexto como cambiante y activo, como organizado y organizador (Grossberg, 2017:29).

A la luz del contextualismo radical, la lente de la interseccionalidad no perdería su pulsión vital, como herramienta de análisis, ya que el ejercicio de teorizar desde lo concreto invalida la supuesta universalidad de los modelos teóricos dominantes, importados desde el norte global (en este caso de Estados Unidos). La lente interseccional desvela las diferentes matrices de dominación estructurantes y estructurales del sistemamundo colonial. Por medio de esta herramienta es posible comprender las marcas de los procesos que esas matrices de opresión han dejado en cuerpos, prácticas, significados, conocimiento y política. Así, coincido con Patrícia de Santana Pinho (2005) en su problematización sobre las formas de abordar las categorías raza y negritud en la academia brasileña, por estar excesivamente centrada en los estudios estadounidenses. La autora señala:

Me parece que el presente brasileño no posee ni la comodidad ilusoria del pasado mítico africano ni la seguridad, igualmente ilusoria, del modelo de sociedad "multirracial" de los Estados Unidos. La forma- 
ción de las ideas de diversidad, etnicidad y "raza", así como de las operaciones cognitivas por medio de las cuales el racismo es ejercido, se da dentro de un contexto específico de cada nación. Si hay un fuerte componente transnacional en las identidades negras de la diáspora, hay también especificidades regionales y nacionales que crean formas distintas de racismo y, por consiguiente, de identidades que se constituyen, en gran parte, a partir del racismo existente. Sabemos que el propio proceso de formación de la nación es, en sí, un proceso de definición de las "razas", por tanto, las estrategias y las políticas públicas de combate al racismo deben de ser formuladas de acuerdo con tales especificidades (De Santana Pinho, 2005:40).

Incluso añadiría que analizar la producción del sujeto político feminista y antirracista, desde el contextualismo radical, conlleva la interpelación al universalismo de los derechos humanos (enunciados desde Europa como institución política), cuyas lógicas de blanqueamiento están definidas por las dos operaciones de la razón occidental: la separación y la determinación. El contexto, entendido como un marco de relaciones vivo, aleatorio, desorganizado y a su vez organizador (Cejas, 2016; Grossberg, 2017), nos ofrece las claves para entender por qué las vidas humanas y no-humanas no importan en cada territorio concreto.

A mi modo de ver, el contextualismo radical, como "un tipo de pensamiento relacional que argumenta que cualquier práctica, evento o representación existe en una red de relaciones" (Restrepo, 2009:9), fortalece la mirada feminista, dejándola en un callejón sin salida ante la posible evasión del compromiso y la responsabilidad que implica esta práctica intelectual teórica. Y esa situación "sin salida" no refiere únicamente a la localización de la sujeto-investigadora, sino también a las teorías, categorías, genealogías y todos los instrumentos de análisis utilizados en la investigación. El compromiso es total. El contextualismo radical, como práctica teórica relacional, incita al ensayo de diferentes escrituras coreográficas para, en ese hacer, ir descubriendo el mejor relato de los procesos creativos, el más comprometido políticamente con la realidad de la cual escribo, aplicando siempre una "metodología de la sospecha", "en otras palabras, la reflexión aguda para evitar las falsas expectativas de una crítica despolitizada sin fuerza transformadora" (Garzón et al., 2014:162).

\section{A modo de conclusión...}

La metodología expuesta en este texto ha sido diseñada antes de realizar el trabajo de campo, por lo que, intuyo, pudiera haber algunos cambios durante el proceso. Sin embargo, me siento preparada para acoger esos desplazamientos venideros, pues camino muy bien acompañada por el sentir-pensamiento de todas las autoras que he citado y las que me orientan en otros capítulos de la investigación.

Las reflexiones en torno a mi relación con las artistas y la práctica escritural son parte de un proceso vital que viene dándose antes de empezar el doctorado, e incluso previo a mi traslado a Brasil —donde viví desde finales de 2013 hasta mediados de 2017- Me atrevería a afirmar que son el resultado de malestares acumulados durante varios años que no supe reconocer como tales en aquel entonces. Así, percibo que la "escritura auto-litigante" (Garzón, 2018b) es una práctica que he venido desarrollando desde hace algún tiempo, gracias a un ejercicio de escucha afectiva-radical llevado a cabo en los diferentes contextos por los que he circulado durante los últimos años. En otro artículo me preguntaba: “¿Por qué volver a bailar?”, una cuestión que podría ser traducida aquí como: ipor qué llevar a cabo una "escritura auto-litigante"? Y decía:

Para perdonarme por decidir ser de ningún lugar; para alivianar el malestar corporal de un peso histórico de cuatrocientos años; para combatir el inconsciente colonizador cuando me dice: "eso nada tiene que ver contigo". Bailar (escribir, investigar, curar) para tener que ver con. "Moverse con para conmoverse" — decía (la coreógrafa) Mónica Valenciano. Volver a bailar implica enfrentar el fantasma de la blanquitud y asumir la responsabilidad de cada coreografía, cada párrafo (Marugán, 2019b). 
Y esto no es otra cosa que aplicar constantemente la "metodología de la sospecha" (Garzón et al., 2014:162) a mi trabajo escritural, investigativo y curatorial, para evitar que el pensamiento crítico pierda su pulsión vital. Por otra parte, la idea de "escritura auto-litigante" tiene una fuerte connotación jurídica y pudiera parecer que tengo el látigo a punto para aplicarme la correspondiente penitencia. El látigo está, pero para otros menesteres $y$, ciertamente, no tengo el menor interés en ninguna práctica procesal y mucho menos en otras orientadas al catolicismo. Sin embargo, la auto-litigación en la escritura sería una brújula para llevar a cabo lo que Trinh T. Minh-Ha define como una obra responsable, esto es, interrogativa, que implique la historia personal en la Historia, que reconozca la diferencia entre experiencia vivida y representación y sea profundamente cuidadosa para no transformar una lucha en objeto de consumo (Minh-Ha, 2015[1991]:54); en definitiva, un trabajo intelectual político que narre una historia más para la postergación del fin del mundo.

\section{Notas}

${ }^{1}$ Digo aparentemente porque Suely Rolnik, en "Esferas da Insurreição" (2018), cuenta que Ailton Krenak y quienes habitaban en su aldea descubrieron que el río Doce ha encontrado en sí mismo una forma de germinar y volver a la vida.

${ }^{2}$ Primera generación del programa de doctorado en Estudios Feministas de la Universidad Autónoma Metropolitana, unidad Xochimilco, Ciudad de México. Investigación guiada por la Dra. Mónica I. Cejas.

${ }^{3}$ El Balé das Iyabás convocaba un domingo al mes a un encuentro de mujeres. Invitaba a una mujer negra que trabajara en un área específica (pedagoga, psicóloga, mãe de santo, activista, bloguera, coreógrafa, etcétera) para presentar su trabajo y debatir sobre el protagonismo de las mujeres negras en esa área. A continuación, se realizaba la lectura de mitos de las Iyabás, que son las orixás femininas en el Candomblé — religión brasileña de matriz africana-, se comentaba la lectura de esos mitos desde perspectivas feministas y antirracistas y la sesión finalizaba con una clase de danza afro.
${ }^{4}$ Narrativa visual de los procesos de las mujeres pedreiras (constructoras de cisternas) en el semiárido brasileño. Ana Lira articula un proceso que va más allá del ensayo visual, produciendo libros de artista, fotozine y exposiciones. Desde la década de los ochenta, las mujeres pedreiras vienen organizándose para autogestionar el recurso más importante de la región, el agua.

${ }^{5}$ Desobedientes en el sentido de no responder a los mandatos teóricos de las disciplinas clásicas, como en este caso sería la historia del arte.

${ }^{6}$ Esta idea la empecé a desarrollar en DEVENIRES, un encuentro artístico sobre feminismos, racialidad y prácticas artísticas, que curé en el Museo Universitario del Chopo, febrero 2020. El conversatorio estuvo dedicado a pensar "Procesos creativos, prácticas situadas, magiar futuros (im)posibles". Se encuentra disponible en https://www.facebook.com/246186207034/videos/633176710584470/

${ }^{7}$ El mestizaje ha sido (continúa siendo) una estrategia de despojo del territorio-tierra y del territorio-cuerpo -como aprendí con las feministas comunitarias, concretamente en un taller con Lorena Cabnal, en marzo de 2018 en la Universidad Nacional Autónoma de México (UNAM).

${ }^{8}$ En Brasil, la formulación del mito de la democracia racial produjo una narrativa de la nación moderna, a partir de retóricas de reconciliación, basada en el mestizaje y orientada a la proyección de un futuro blanco o blanqueado del país. Según Gilberto Freyre, en "Casa-Grande \& Senzala" (1985[1933]), el mestizaje fue una práctica ampliamente extendida que corrigió la distancia social entre la casa grande y la senzala (el espacio doméstico habitado por las personas esclavizadas). El antropólogo brasileño positivó el mestizaje en detrimento de una raza pura, contraponiendo los trópicos a Europa y apagando las diferencias étnico-raciales en beneficio de una verdadera identidad colectiva brasileña.

${ }^{9}$ Rehúso citar el nombre del presidente para no contribuir a aumentar su visibilidad en el espacio virtual.

${ }^{10}$ Sin que lo que nos separe sea concebido negativamente y sin pretender superar las diferencias apelando a una igualdad utópica e inalcanzable. 
${ }^{11}$ Una identidad mucho más compleja que la marcada por mi nacionalidad y donde la interseccionalidad es fundamental para posicionarme y direccionar esa "escritura contra una misma". Este tema lo empecé a desarrollar en el artículo "Ejercicio auto-etnográfico: blanquitud, mestizaje cultural y nomadismo feminista” (Marugán, 2020).

${ }^{12}$ Una ficción material que produce mundo, desigualdades, organiza y reorganiza opresiones, inventa crisis...

${ }^{13}$ Programa disponible en http://www.chopo.unam.mx/ teatro/devenires.html

${ }^{14}$ Los quilombos son las aldeas que crearon los esclavos huidos de las haciendas. Es un término de origen angoleño. Estos espacios de resistencia estaban escondidos en lugares inaccesibles, montañas, en grutas de difícil acceso, en medio del bosque, y en ellos los esclavos conseguían vivir una vida libre de maltratos. El más famoso es el Quilombo dos Palmares, ubicado actualmente en el estado de Alagoas. Hoy en día todavía existen comunidades quilombolas en diferentes partes del país, pero sobre todo en el Recôncavo Bahiano y en el estado de Río de Janeiro. Son comunidades que reciben escasos recursos del Estado brasileño, que han desarrollado economías de autoabastecimiento y que tienen una producción de conocimiento y de cultura muy poderosa, aunque de difícil acceso todavía hoy.

${ }^{15}$ En el candomblé, religión brasileña de matriz africana, la comunidad se reúne en una casa llamada terreiro para la celebración de sus rituales. A menudo, estas "casas" funcionan como espacios de articulación de proyectos sociales, ya que suelen estar ubicadas en áreas marginalizadas de las ciudades, donde se concentra la mayor densidad de población negra.

\section{Referencias}

Ahmed, Sara (2017). Vivir una vida feminista. Barcelona: Bellaterra.

Brah, Avtar (2004). "Diferencia, diversidad y diferenciación". En bell hooks et al., Otras inapropiables. Feminismo desde las fronteras. Madrid: Traficantes de Sueños, pp. 107-136.

Cardoso, Lourenço (2010). "Branquitude acrítica e crítica: a supremacia racial e o branco antirracista”. En Re- vista Latinoamericana de Ciencias Sociales, Niñezy Juventud, 8(1), 607-630.

Cejas, Mónica Inés (2016). "Introducción. Prácticas irreverentes”. En Mónica I. Cejas (coord.), Feminismo, cultura y política. Prácticas irreverentes. México: Universidad Autónoma Metropolitana-Xochimilco, pp. 127-166.

De Santana Pinho, Patrícia (2005). "Descentrando os Estados Unidos nos estudos sobre negritude no Brasil". En Revista Brasileira de Ciências Sociais, 20(59), octubre, 37-50.

Federici, Silvia (2004). Calibán y la bruja. Mujeres cuerpo y acumulación originaria. Madrid: Traficantes de Sueños.

Ferreira da Silva, Denise (2016). "Sobre diferença sem separabilidade". Catálogo de la 32ª Bienal de Artes de São Paulo Incerteza Viva. São Paulo, pp. 57-65.

Freyre, Gilberto (1985[1933]). Casa-grande y senzala. España: Biblioteca Ayacucho.

Hall, Stuart (2011). "Cultural studies 'at large"'. En Stuart Hall y Miguel Mellino, La cultura y el poder. Conversaciones sobre los cultural studies. Buenos Aires: Amorrortu.

Garzón Martínez, María Teresa (2018a). "Defender Fantasía: Hacia un modelo de crítica cultural feminista". En Revista Ístimica, 22, 77-99.

Garzón Martínez, María Teresa (2018b). "Oximoron. Blanquitud y feminismo descolonial en Abya Ayala”. En Descentrada, 2(2), 1-13.

Garzón Martínez, María Teresa, Mónica Cejas, Merarit Viera, Luisa Fernanda Hernández Herse y Linda Daniela Villegas Mercado (2014). “Ninguna guerra en mi nombre"': feminismo y estudios culturales en Latinoamérica”. En Nómadas, 40, 158-173.

Grossberg, Lawrence (2009). "El corazón de los estudios culturales: contextualidad, construccionismo y complejidad". En Tábula Rasa, 10, 13-48.

Grossberg, Lawrence (2017). "Stuart Hall: diez lecciones para los estudios culturales". En Intervenciones en Estudios Culturales, 4, 25-37.

Jablonka, Ivan (2016). La historia es una literatura contemporánea. Manifiesto por las ciencias sociales. Buenos Aires: Fondo de Cultura Económica.

Krenak, Ailton (2019). Ideias para adiar o fim do mundo. São Paulo: Companhia das Letras. 
Lira, Ana y Paola María Marugán Ricard (2020). “TERRANE”. En Cadernos de Subjetividade, 20, 6-19. Disponible en https://revistas.pucsp.br/cadernossubjetividade/article/view/46068?fbclid=IwARljODDEQ4uEFNxgNm 4RCn0tTcE-LcVlVrWjWH5_FG19Iz8p7JIJhMjtIZE

Marugán Ricart, Paola María (2019a). "Vivências: un ensayo de otros mundos posibles". Ponencia presentada en las XIV Jornadas Nacionales de Historias de las Mujeres y el IX Congreso Iberoamericano de Estudios de Género, en Mar del Plata, Argentina, julio. Disponible en https://www.academia. edu/41619287/_Viv\%C3\%AAncias_un_ensayo_de otros_mundos_posibles

Marugán Ricart, Paola María (2019b). "Notas para empezar a bailar un texto. Mónica Valenciano: el cuerpo como lugar de aparición”. En Errantes, 4 de diciembre. Disponible en http://errantesfanzine.com/2019/12/24/ notas-para-empezar-a-bailar-un-texto-monica-valenciano-el-cuerpo-como-lugar-de-aparicion/

Marugán Ricart, Paola María (2020). "Ejercicio auto-etnográfico: blanquitud, mestizaje cultural y nomadismo feminista". En Periódicus, 1(12), 204-222.

Minh-Ha, Trinh T. (2015[1991]). "Questões de imagem e política". En Carla Maia y Luís Felipe Flores (coords.), O cinema de Trinh T. Minh-ha. Belo Horizonte: Caixa Cultural, Gráfica O Lutador.
Nascimento, Abdias (2018[1976]). "Arte Afro-brasileira: um espírito libertador”. En Histórias afro-atlânticas. São Paulo: Museo de Arte de São Paulo, Instituto Tomie Ohtake, pp. 32-39.

Pinacoteca de São Paulo (2019). "Roda de Conversa Grada Kilomba e Djamila Ribeiro" [vídeo], 6 de julio. Disponible en https://www.youtube.com/ watch? $=$ ovSKrDLs9Ro

Restrepo, Eduardo (2009). “Antropología y estudios culturales: distinciones, tensiones y confluencias". S.p.i. Disponible en http://w.ram-wan.net/restrepo/documentos/notas-antropo-eccss.doc (consultado el 25 de marzo de 2020).

Richard, Nelly (2009). "La crítica feminista como modelo de crítica cultural". En Debate Feminista, 40, 75-85.

Rolnik, Suely (2018). Esferas de la insurrección. Apuntes para descolonizar el inconsciente. Buenos Aires: Tinta Limón.

Silva Bento, Maria Aparecida (2002). "Branqueamento e branquitude no Brasil”. En Iray Carone y Maria Aparecida Silva Bento (coords.), Psicología social do racismo - estudos sobre branquitude e branqueamento no Brasil. Petrópolis, RJ: Vozes, pp. 25-58.

Sovik, Liv (2005). "Por que tenho razão: branquitude, Estudos Culturais e a vontade de verdade acadêmica en Contemporânea". En Revista de Comunicação e Cultura, 3(2), julio-diciembre, 159-180. 